\title{
The role of lipoic acid in the protection against of metallic pollutant effects in the shrimp Litopenaeus vannamei (Crustacea, Decapoda) ${ }^{\text {th }}$
}

\author{
Roberta Oliveira Lobato ${ }^{\mathrm{a}, \mathrm{b}}$, Silvana Manske Nunes a, Wilson Wasielesky ${ }^{\mathrm{c}, \mathrm{d}}$, Daniele Fattorini ${ }^{\mathrm{e}}$, \\ Francesco Regoli e , José Marìa Monserrat ${ }^{\mathrm{a}, \mathrm{b}, \mathrm{d}}$, Juliane Ventura-Lima ${ }^{\mathrm{a}, \mathrm{b}, *}$ \\ a Instituto de Ciências Biológicas (ICB), Universidade Federal do Rio Grande-FURG, Rio Grande, RS, Brazil \\ b Programa de Pós-Graduação em Ciências Fisiológicas-Fisiologia Animal Comparada-FURG, Brazil \\ ' Instituto de Oceanografia (IO), Universidade Federal do Rio Grande-FURG, Brazil \\ d Programa de Pós-Graduação em Aquacultura-FURG, Brazil \\ e Dipartimento di Scienze della Vita e dell'Ambiente, Università Politecnica delle Marche, 60131, Ancona, Italy
}

\section{A R T I C L E I N F O}

\section{Article history:}

Received 29 November 2012

Received in revised form 9 March 2013

Accepted 11 March 2013

Available online 16 March 2013

\section{Keywords:}

Litopenaeus vannamei

Antioxidant responses

Lipoic acid

Arsenic

Cadmium

Chemoprevention

\begin{abstract}
A B S T R A C T
The effects of cadmium (Cd) and arsenic (As), dosed alone or in combination have been poorly investigated in crustaceans. Besides, it is not known if dietary supplementation of exogenous antioxidants, like lipoic acid (LA), might prevent or even reverse toxic effects of Cd and As. The objective of the present study was to evaluate the role of lipoic acid in modulating biochemical responses after $\mathrm{Cd}$ and As exposures in Litopenaeus vannamei. Muscle from shrimp exposed to $\mathrm{Cd}$ alone or $\mathrm{Cd}+$ As showed a decrease in glutathione (GSH) levels, while the pre-treatment with LA reversed this situation. In this tissue, the pre-treatment with LA also induced an increase in glutathione-S-transferase (GST) activity in all groups.

In hepatopancreas it was observed a marked accumulation of $\mathrm{Cd}$ and $\mathrm{As}$, a decrease in the reactive oxygen species (ROS) concentration in response to Cd exposure alone (-LA); concomitant in the same group it was observed an increment of metallothionein-like content. As exposure induced an increase in GSH levels but LA reversed this increase. Also, LA showed to increase the GST activity in all groups treated. Besides, in this organ LA showed to augment total antioxidant competence. Obtained results indicate that LA can be used as a chemo-protectant against oxidative insults in shrimp.
\end{abstract}

@ 2013 Elsevier Inc. All rights reserved.

\section{Introduction}

The Patos Lagoon estuary is a potential shrimp culture area in Southern Brazil. This region is partly contaminated by As and Cd associated to activities of local fertilizer factories (Mirlean and Roisemberg, 2006), potentially representing a risk for accumulation in aquatic organisms and exposure of humans through food consumption (Hossain, 2006; Chang et al., 2009). The Pacific white shrimp Litopenaeus vannamei (Crustacea; Decapoda) is an important species for human consumption, but few data are available on its sensitivity to cadmium and/or arsenic.

Cadmium can induce oxidative stress in shrimp, as observed in haemocytes and hepatopancreas cells of L. vannamei, where this element caused a time and dose-dependent respiratory burst increase, leading to overproduction of reactive oxygen species (ROS), release

\footnotetext{
This paper was presented at the 'First International Conference on Oxidative Stress in Aquatic Ecosystems' held in San Jose del Cabo, Baja California Sur, Mexico on November 20-24, 2012.

* Corresponding author at: Instituto de Ciências Biológicas (ICB), Universidade Federal do Rio Grande-FURG, Rio Grande, RS, Brazil. Tel./fax: + 555332935249.

E-mail address: juliane_ventura@yahoo.com.br (J. Ventura-Lima).
}

of $\mathrm{Ca}^{2+}$ from sarcoplasmatic reticulum, activation of endonucleases and DNA damage (Chang et al., 2009).

Cadmium toxicity is also related to modulation of antioxidant system and redox state of cells, modification in protein structure, lipid peroxidation and altered expression of various proteins (Soares et al., 2008). On the other hand, cadmium is a well known inducer of metallothioneins (MTs), low molecular weight proteins, rich in cysteine moieties with metal-binding and ROS-scavenging capability (Viarengo et al., 1997; Anderson et al., 1999).

Modulation of glutathione (GSH) metabolism seems a typical response to As exposure, probably mediated by the activation of the transcription factor Nrf2 which, through its interaction with the antioxidant response element (ARE) controls the transcription of a battery of antioxidant and detoxification genes including glutamate-cysteine ligase (GCL), glutathione-S-transferase (GST), heme-oxigenase-I (Wang et al., 2007). In some species the modulation of GSH system is sufficient to neutralize pro-oxidant challenges, while in others oxidative damages will still appear. In fact, in gills of Danio rerio after arsenic exposure it was observed that there was an increase of GSH levels concomitantly with a higher GCL activity, the key enzyme in the synthesis of GSH (Ventura-Lima et al., 2009a), while in liver of Carassius auratus the increase of GSH levels could not prevent the appearance of oxidative 
effects of arsenic (Bagyuokova et al., 2007). Less investigated are pro-oxidant effects of arsenic in shrimp or other crustacean species.

Some studies have shown that the administration of exogenous antioxidants can prevent oxidative damage and stimulate the immune system in mammals and aquatic animals (Sant'Ana and Mancini-Filho, 2000; Hsieh et al., 2008). Among these, the redox pair, lipoic acid (LA) and its reduced form dihydrolipoic acid (DHLA) are powerful compounds, with amphipathic characteristics, able to quench free radicals, chelate metals and regenerate other antioxidants (Packer et al., 1995). The fish Corydora paleatus supplemented with LA in food, exhibited a decrease of ROS concentration and increase of GST activity in brain, suggesting that LA can improve the detoxification capacity acting as a neuroprotector; besides LA showed to decrease the levels of oxidized proteins in muscle, improving the antioxidant capacity of the animal (Monserrat et al., 2008).

Few is known about the effect of LA in shrimp and the potential chemoprotector effect against metallic pollutant such as $\mathrm{Cd}$ and As. So, the potential benefits and chemo-protective effects of LA in L. vannamei were evaluated in shrimp exposed to high concentrations of the prooxidant elements cadmium and arsenic dosed alone or in combination. The choice of this high concentration to both metals was an attempt to induce characteristic responses of $\mathrm{Cd}$ and $\mathrm{As}$ and in this way to observe the role of lipoic acid as a possible chemo protectant against metallic pollutants effects. The period of exposure was fixed in two days because previous studies have shown that this time is sufficient to induce biochemical responses in some aquatic organisms after $\mathrm{Cd}$ or As exposure (Ventura-Lima et al., 2009a; Dabas et al., 2012).

So, the main objectives of this study were to evaluate: (1) the biochemical responses of cadmium and arsenic using biomarkers of oxidative stress in muscle and hepatopancreas of L.vannamei; (2) the benefits of LA pretreatment in prevention or reversion of oxidative effects of metals; (3) the benefits of LA added to the diet in terms of antioxidant capacity of muscle and hepatopancreas.

\section{Materials and methods}

\subsection{Maintenance of shrimp and experimental design}

Shrimp were obtained from Estação Marinha de Aquacultura (EMA), Instituto de Oceanografia, Universidade Federal do Rio Grande-FURG (Rio Grande, Brazil), and transferred to the Instituto de Ciências Biológicas (ICB) of the same University and acclimated in tanks under controlled parameters ( $\mathrm{pH}$ around 8.0; salinity 30\%, photoperiod 12L:12D, feeding twice at day) at least during 15 days before the beginning of experiments. After this period, the shrimp were divided in two experimental groups: 1) organisms exposed for 2 days only to $1 \mathrm{mg} / \mathrm{L} \mathrm{of} \mathrm{Cd}$, or $1 \mathrm{mg} / \mathrm{L}$ of As, or $1 \mathrm{mg} / \mathrm{L}$ of $\mathrm{Cd}+1 \mathrm{mg} / \mathrm{L}$ of As (Cd as $\mathrm{CdCl}_{2} \cdot \mathrm{H}_{2} \mathrm{O}$ from Merck; $\mathrm{As}^{\mathrm{III}}$ as $\mathrm{NaAsO}_{2}$, from VETEC; both PA grade), and 2) organisms that received during four weeks a lipoic acid-enriched diet (70 $\mathrm{mg} \mathrm{LA} / \mathrm{kg}$ of body mass) before exposure during 2 days to various combinations of $\mathrm{Cd}$ and/or As. A group exposed only to LA during four weeks also was ran in parallel.

\subsection{Experiments with lipoic acid}

Thirty shrimp were randomly placed in aquaria and received or not lipoic acid ( + LA and $-\mathrm{LA}$, respectively) through diet during four weeks. The food was prepared according to Monserrat et al. (2008), using commercial ration (Purina, $45 \%$ of crude protein) enriched with lipoic acid (Sigma, USA), mixed with ultrapure water and dried at $50{ }^{\circ} \mathrm{C}$ to obtain pellets. The LA concentration utilized in this study was $70 \mathrm{mg} / \mathrm{kg}$ of body mass provided twice per day with a daily supply of $1 \%$ of body weight (Samuel et al., 2004). Every week, the shrimp were measured to adjust the LA concentration and diet quantity according to their weight increase. The control group received only commercial diet prepared with the same procedure but without adding LA. After
4 weeks, the shrimp were exposed to cadmium and/or arsenic as previously described.

\subsection{Determination of total cadmium and arsenic}

Arsenic and cadmium were determined following previously validated procedures only in the experimental groups exposed to metals without pre-treatment with lipoic acid (Fattorini et al., 2008). Samples were digested under pressure with nitric acid and hydrogen peroxide (5:1) using a microwave, and the elements were analyzed by atomic absorption spectrophotometry, with flame (Varian, SpectrAA 220FS) and electrofurnace atomization with Zeeman effect (Varian SpectrAA 240Z). For all chemical analyses, quality assurance and quality control were checked by processing blank and reference standard materials (Mussel Tissue Standard Reference Materials [SRM] 2977, National Institute of Standards and Technology). The concentrations obtained from these SRM were always within the 95\% confidence intervals of the certified values. Cd and As tissue concentrations were expressed as $\mu \mathrm{g} / \mathrm{g} \mathrm{dw}$ (means values \pm standard deviation, $\mathrm{n}=5$ for each tissue).

\subsection{Preparation of samples for biochemical analyses}

Muscle and hepatopancreas organs were dissected and homogenized $(1: 4 \mathrm{p} / \mathrm{v})$ in buffer containing $100 \mathrm{mM}$ Tris-HCl, 2 mM EDTA, $5 \mathrm{mM}$ $\mathrm{MgCl}_{2}, 0.05 \mathrm{mM}$ PMSF and $\mathrm{pH} 7.75$, centrifuged at 10,000 $\mathrm{g}$ for $20 \mathrm{~min}$ at $4{ }^{\circ} \mathrm{C}$, and the supernatant used for antioxidant measurements. Total proteins in the samples were measured following Biuret method utilizing microplate reader (Biotel EL $\times 800$ ). Only determination of ROS concentration was performed with fresh tissue. For the other measurements, aliquots of the supernatants were stored at $-80^{\circ} \mathrm{C}$.

\subsection{Reactive oxygen species (ROS) measurement}

After dissection, muscle and hepatopancreas were immediately homogenized in cold buffer and centrifuged (10,000 g, $20 \mathrm{~min})$. The supernatants were kept, the protein concentration determined and then adjusted to a final concentration of $2 \mathrm{mg} / \mathrm{mL}$. For ROS quantification 2'7'-dichlorofluorscein-diacetate $\left(\mathrm{H}_{2} \mathrm{DCF}-\mathrm{DA}\right)$ was utilized which generates a fluorochrome detected at 485/520 nm wavelength for excitation and emission respectively (Ferreira-Cravo et al., 2007).

\subsection{Activity of glutathione S-transferase}

GST (EC 2.5.1.18) activity was based on methodology described by Habig and Jakoby (1981) where the absorbance generated by the conjugation of $1 \mathrm{mM}$ glutathione (GSH, Sigma-Aldrich) with $1 \mathrm{mM}$ of 1-chloro-2,4-dinitrobenzene (CDNB, Sigma-Aldrich) was monitored at $340 \mathrm{~nm}$.

\subsection{Reduced glutathione (GSH) levels}

This analysis followed the methodology described by White et al. (2003), measuring the reaction of GSH with naphthalene dicarboxialdehyde (NDA, Invitrogen) that forms cyclized products (GSH-NDA) with high fluorescence detected in microplate reader (Victor 2, Perkin Elmer) at 485/530 excitation/emission wavelengths respectively.

\subsection{Antioxidant capacity against peroxyl radical}

This analysis was performed through the generation of peroxyl radical by thermal decomposition of ABAP $\left(2,2^{\prime}\right.$-azobis ( 2 methylpropionamidine) dihydrochloride) at $35{ }^{\circ} \mathrm{C}$ (Winston et al., 1998 ) that reacts with $\mathrm{H}_{2}$ DCFDA after de-acetylation of this probe and, after ROS oxidation, forms a fluorescent compound (DCF), detected at $485 / 530 \mathrm{~nm}$ for excitation/emission in a microplate reader (Victor 2, 
Perkin Elmer). Total fluorescence generation was measured along $30 \mathrm{~min}$, adjusting the fluorescence data to a second order polynomial function. The total antioxidant capacity against peroxyl radical was quantified by the relative area with and without ABAP where high relative fluorescence area indicates low antioxidant competence, once high fluorescence levels were obtained after addition of ABAP meaning low capacity to neutralize peroxyl radicals (Amado et al., 2009).

\subsection{Lipid peroxides}

Oxidative damage was analyzed following the protocol described by Oakes and Van Der Kraak (2003). Lipid peroxides were measured as thiobarbituric acid reactive substances (TBARS) by a fluorimetric method at $520 / 580 \mathrm{~nm}$ for excitation/emission wavelengths. The results were expressed as nmol TBARS/mg of protein using tetramethoxypropane (TMP, ACROS organics) as standard.

\subsection{Determination of metallothionein-like (MT-L) proteins content}

The organs of shrimp exposed to $\mathrm{Cd}$ (with and without LA pre-treatment) were homogenized in a specific buffer (sucrose $500 \mathrm{mM}$, Tris- $\mathrm{HCl} 20 \mathrm{mM}$, PMSF $0.5 \mathrm{mM}$ and $\beta$-mercaptoethanol $0.01 \%, \mathrm{pH} 8.6$ ). The concentration of metallothioneins in the homogenates was performed by spectrophotometry (405 nm) using DTNB (5,5-dithio-bis 2 nitrobenzoic acid; Sigma-Aldrich) (Viarengo et al., 1997). Results were expressed in terms of GSH equivalents ( $\mu \mathrm{mol} \mathrm{GSH} / \mathrm{g}$ of tissue wet mass) using GSH standard solutions for the calibration curve.

\subsection{Statistical analysis}

Statistical differences between various parameters were analyzed through analysis of variance (ANOVA). Pos hoc comparisons were made using Newman-Keuls test or orthogonal contrast. A factorial ANOVA was run for all variables taking as factor the treatments (control, $\mathrm{Cd}$, As and $\mathrm{Cd}+\mathrm{As}$ ) and pre-treatment with or without LA. Statistical requirements (assumptions of normality and variance homogeneity) were previously analyzed and mathematical transformation applied when necessary (Zar, 1984). In all cases significance level was fixed in $5 \%$.

\section{Results}

Organ concentrations of arsenic and cadmium did not reveal any significant bioaccumulation in muscle of exposed shrimp $(\mathrm{p}<0.05)$, while these elements were markedly accumulated in hepatopancreas $(\mathrm{p}<0.05)$ (Table 1). In this organ, arsenic concentrations exhibited similar values in organisms exposed to the metal dosed alone or in combination with cadmium; on the other hand, cadmium accumulation was significantly lowered by the contemporary exposure to arsenic when compared to organisms treated with cadmium alone (Table 1).

ROS concentration did not vary $(p>0.05)$ in muscle after exposure to various combinations of metals independently of the pre-treatment (+ LA or - LA) (Fig. 1a). A significant decrease of ROS was observed in hepatopancreas of the control organisms supplemented with lipoic acid $(+\mathrm{LA})$ compared to the control group without LA $(\mathrm{p}<0.05)$ (Fig. 1b); a similar effect was obtained in shrimp after Cd exposure when compared with the control $(-\mathrm{LA})(\mathrm{p}<0.05)$.

The pre-treatment with lipoic acid (+ LA) increased GST activity in muscle during all treatments when compared with respective LA groups $(\mathrm{p}<0.05)$, with the only exception of $\mathrm{Cd}+$ As co-exposure (Fig. 2a). Also in hepatopancreas pre-treatment with LA resulted in increased enzymatic activity in all groups $(\mathrm{p}<0.05)$, except in organisms exposed only to Cd (Fig. 2b).

GSH concentration in muscle decreased in shrimp not pre-exposed to LA and treated with $\mathrm{Cd}(\mathrm{p}<0.05)$, while this result was reversed by pre-treatment with LA ( $\mathrm{p}<0.05)$. LA induced an increase in GSH
Table 1

Arsenic and cadmium concentrations ( $\mu \mathrm{g} / \mathrm{g}$ dry mass) in hepatopancreas and muscle of L. vannamei exposed during two days to As and/or Cd $(1 \mathrm{mg} / \mathrm{L})$ dosed alone or in combination.

\begin{tabular}{llcc}
\hline Treatment & & Total arsenic & Total cadmium \\
\hline Control & Muscle & $0.616 \pm 0.214^{\mathrm{a}}$ & $0.012 \pm 0.004^{\mathrm{a}}$ \\
& Hepatopancreas & $2.11 \pm 0.26^{\mathrm{b}}$ & $0.53 \pm 0.05^{\mathrm{b}}$ \\
Cadmium & Muscle & $0.447 \pm 0.147^{\mathrm{a}}$ & $0.338 \pm 0.060^{\mathrm{a}}$ \\
& Hepatopancreas & $3.32 \pm 1.58^{\mathrm{b}}$ & $67.39 \pm 12.82^{\mathrm{b}^{*}}$ \\
Arsenic & Muscle & $1.036 \pm 0.222^{\mathrm{a}}$ & $0.010 \pm 0.002^{\mathrm{a}}$ \\
& Hepatopancreas & $7.97 \pm 1.49^{\mathrm{b}^{*}}$ & $1.04 \pm 0.45^{\mathrm{b}}$ \\
$\mathrm{Cd}+$ As & Muscle & $1.180 \pm 0.27^{\mathrm{a}}$ & $0.318 \pm 0.028$ \\
& Hepatopancreas & $6.32 \pm 1.58^{\mathrm{b}^{*}}$ & $20.6 \pm 7.85^{\mathrm{b}^{*}}$ \\
\hline
\end{tabular}

Concentrations are expressed as means \pm standard deviation $(n=3)$. Different letters indicate significant differences between tissues. Asterisks $\left({ }^{*}\right)$ indicate values differ significantly from those in the control group and hash marks $\left({ }^{\#}\right)$ indicate differences between group exposed to mixture of $\mathrm{Cd}$ and As when compared with group exposed only to $\mathrm{Cd}$.

levels also in organisms exposed to $\mathrm{Cd}+\mathrm{As}(\mathrm{p}<0.05)$ (Fig. 3a). In the hepatopancreas of shrimp exposed only to As it was verified an increase in GSH levels when compared with control group without LA $(\mathrm{p}<0.05)$. Interestingly, LA pre-treatment reversed this effect $(p<0.05)$. Also the + LA control group showed higher GSH levels than - LA control group ( $<<0.05)$ (Fig. 3b).

No variation of total antioxidant competence against peroxyl radicals was observed in muscle independent of treatment ( $p<0.05$; Fig. 4a). However, in hepatopancreas an increase of total antioxidant capacity (lower relative area) was observed after pre-treatment with LA in the control and $\mathrm{Cd}+$ As groups compared with the same groups without LA ( $\mathrm{p}<0.05)$ (Fig. 4b).

Metal exposures $(\mathrm{Cd}$, As and $\mathrm{Cd}+\mathrm{As}$ ) did not induce any change in terms of TBARS content ( $p>0.05$ ) in muscle of L. vannamei, but all LA pre-treated groups showed a marked decrease of TBARS levels
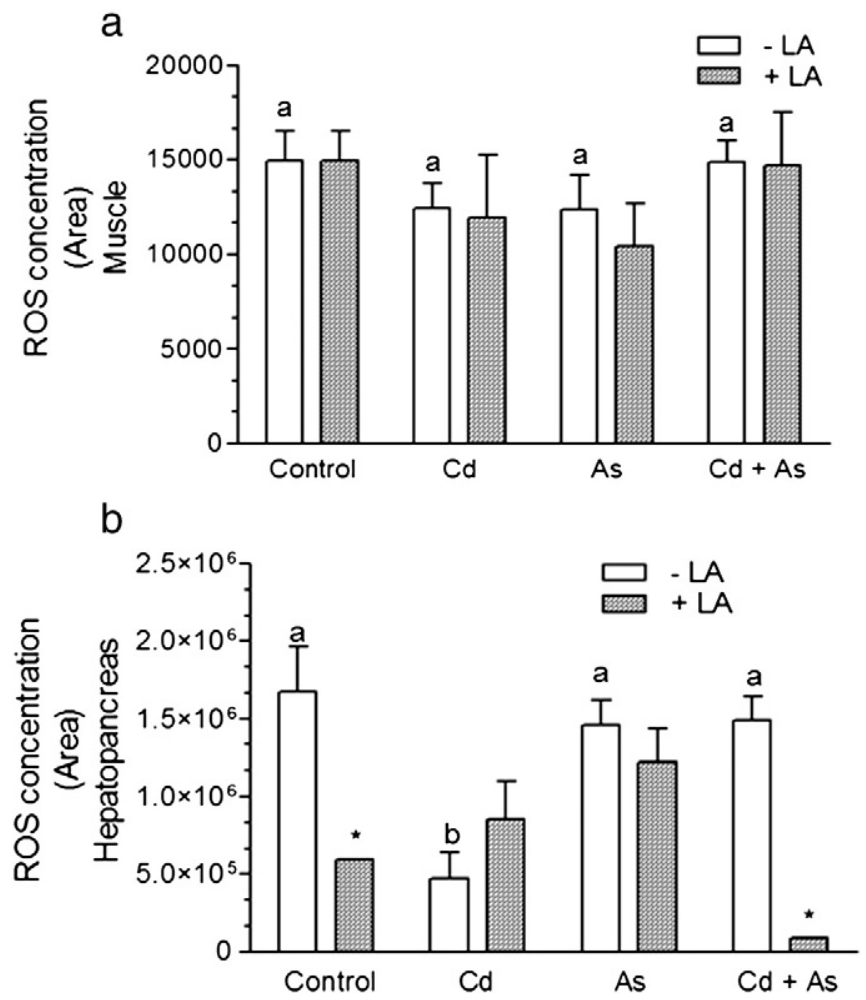

Fig. 1. Reactive oxygen species (ROS) concentration (expressed by area). (a) Muscle; (b) hepatopancreas. Different letters indicate significant differences $(\mathrm{p}<0.05)$ compared to control group ( - LA). Asterisks $\left({ }^{*}\right)$ indicate significant difference $(\mathrm{p}<0.05)$ between group pre-treated with LA ( + LA) when compared with same treatment without LA ( - LA). Data are expressed as mean \pm 1 standard error $(n=4-6)$. 

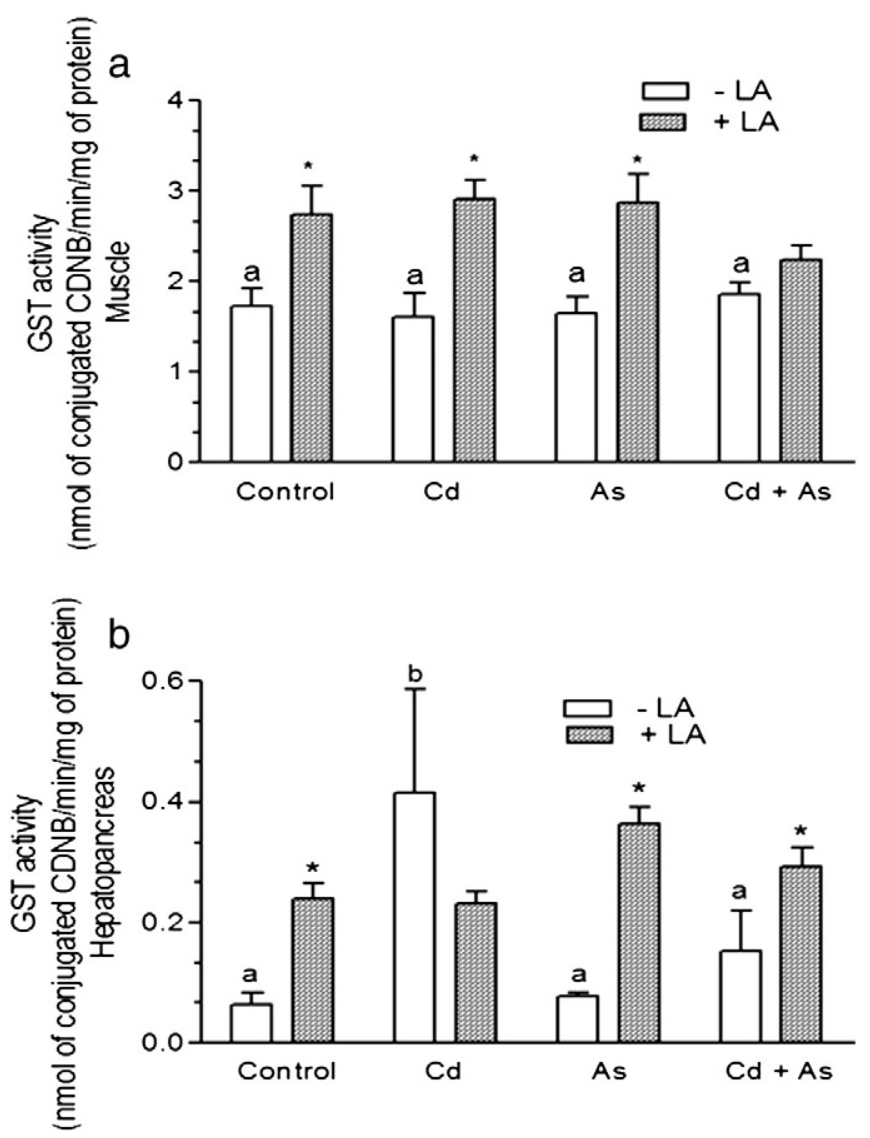

Fig. 2. Glutathione-S-transferase (GST) activity (expressed by nmol conjugated CDNB/ $\mathrm{min} / \mathrm{mg}$ of protein). (a) Muscle; (b) Hepatopancreas. Different letters indicate significant differences $(p<0.05)$ compared to control group $(-\mathrm{LA})$. Asterisks $\left(^{*}\right)$ indicate significant difference $(\mathrm{p}<0.05)$ between group pre-treated with LA $(+\mathrm{LA})$ when compared with same treatment without LA $(-\mathrm{LA})$. Data are expressed as mean \pm 1 standard error $(n=3-6)$.

$(p<0.05)$ (Fig. 5a). Similar effects were not observed in hepatopancreas $(p>0.05)$ (Fig. 5b).

Metallothionein-like proteins were not significantly changed in muscle after $\mathrm{Cd}$ exposure compared with control group independent of treatment with LA ( $p>0.05$ ) (Fig. 6a). In hepatopancreas of shrimp not pre-treated with LA, higher levels of metallothionein like were measured after Cd exposure compared with control group without LA $(\mathrm{p}<0.05)$, while the administration of LA reverted this result $(\mathrm{p}<0.05)$, but caused significantly higher levels of MTs in the control group (+LA) when compared with respective - LA control organisms $(p<0.05)$ (Fig. 6b).

\section{Discussion}

Relatively few studies have compared accumulation of metals in shrimp organs (Frías-Espericueta et al., 2009) and our study demonstrated a significant increase of As and Cd only in hepatopancreas; the lack of accumulation in muscle of exposed organisms (Table 1) has important implications considering that these organs are those primarily consumed by humans.

Even though Cd and As are known to induce adverse effects in aquatic organisms, no oxidative toxicity was caused by these metals on shrimp organs. In fact a decreased ROS concentration was measured in hepatopancreas of shrimp exposed to $\mathrm{Cd}$ alone when compared with the control group (-LA) (Fig. 1b); this effect was not obtained in organisms co-exposed with As which, however, also exhibited a more limited cadmium accumulation. Contrasting with our findings, Cd was shown to induce the production of reactive oxygen species in digestive gland of mussel Crenomytilus grayanus (Chelonin et al., 2005) and in haemocytes
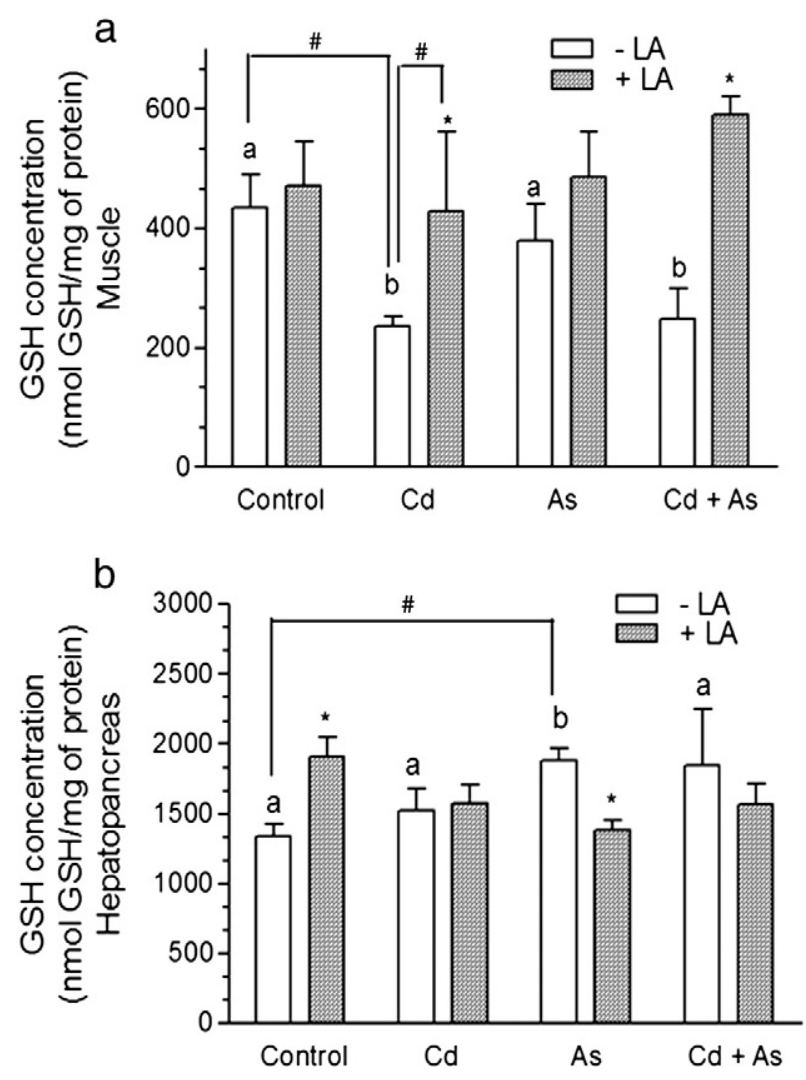

Fig. 3. Glutathione reduced (GSH) content (expressed as nmol GSH/mg of protein) (a) Muscle; (b) hepatopancreas. Different letters indicate significant differences $(\mathrm{p}<0.05)$ compared to control group $(-\mathrm{LA})$. Asterisks $\left({ }^{*}\right)$ indicate significant difference $(\mathrm{p}<0.05)$ between group pre-treated with LA $(+\mathrm{LA})$ when compared with same treatment without LA $(-\mathrm{LA})$. Hash $(\#)$ indicates significant differences $(\mathrm{p}<0.05)$ between treatments connected by solid lines. Data are expressed as mean \pm 1 standard error $(\mathrm{n}=3-6)$.

of gastropod Haliotis tuberculata (Latire et al., 2012), while a decrease of ROS concentration after $\mathrm{Cd}$ exposure has been associated to induction of metallothioneins in hemocytes of Crassostrea virginica (Roesijadi et al., 1997).

Also in our study the decrease of ROS concentration in hepatopancreas of Cd exposed shrimp was paralleled by an increase in MT-L levels (Fig. 6b), suggesting that thiolic groups can both bind the metal and scavenge produced ROS. Another pathway of Cd detoxification is suggested by the significant increase of GST activity (Fig. 2b) which, through conjugation reactions with GSH, further contributes to reduce Cd reactivity. Increased GST after Cd exposure was observed in liver, gills and olfactory tissues of Oncorhynchus kisutch (Espinoza et al., 2012), and in liver, gills and kidneys of freshwater fish Chana punctatus (Dabas et al., 2012). Reduced ROS concentration, enhanced levels of MTLs and GST are consistent with the absence of lipid peroxidation damages observed in tissues of Cd exposed shrimp (Fig. 5b).

Reduced glutathione is typically present in high concentration within cells (up to $10 \mathrm{mM}$ ), being a major contributor to maintain cell redox state (Halliwell and Gutteridge, 2007). Besides, acting as substrate for antioxidant enzymes, GSH also prevents protein thiol groups from oxidation. In this study no variations in terms of GSH levels were observed in hepatopancreas after $\mathrm{Cd}$ exposure, while a significant decrease was measured in muscle (Fig. 3a), indicating for these organs a potentially higher susceptibility to oxidative damages which, however, did not appear after $48 \mathrm{~h}$ exposure (Fig. 5a).

Very limited oxidative responses were also caused in shrimp by acute exposure to As, revealing only a significant increase of GSH levels in hepatopancreas (Fig. 3b) when compared with control groups (-LA). A similar result was observed in gills of $D$. rerio and liver of Cyprinus carpio 
a

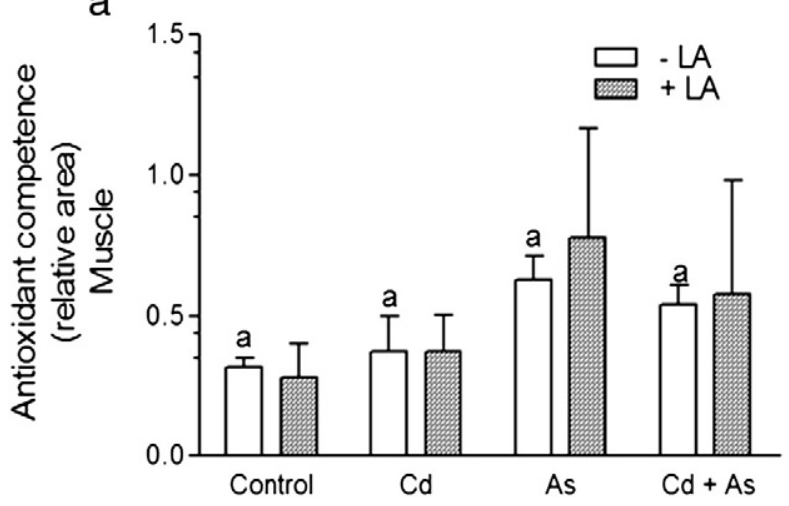

b

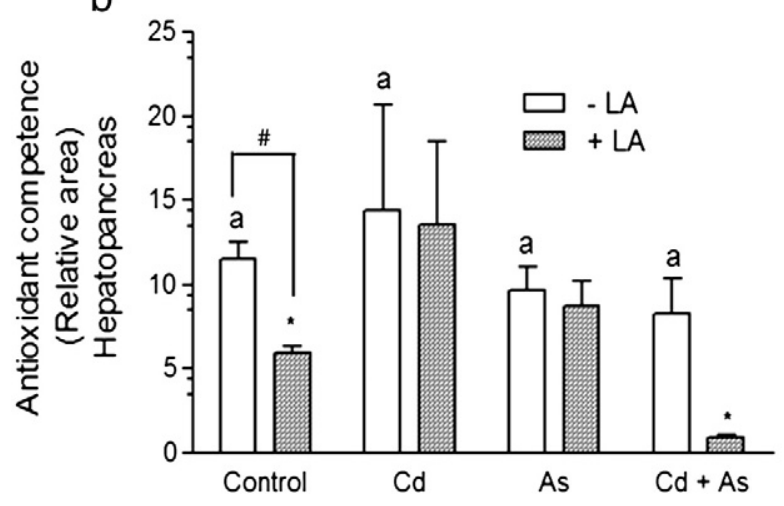

Fig. 4. Antioxidant competence against peroxyl radicals (expressed by relative area). (a) Muscle; (b) hepatopancreas. Different letters indicate significant differences $(\mathrm{p}<0.05)$ compared to control group ( $-\mathrm{LA})$. Asterisks $\left(^{*}\right)$ indicate significant difference $(\mathrm{p}<0.05)$ between group pre-treated with LA ( $+\mathrm{LA})$ when compared with same treatment without LA $(-L A)$. Hash $(\#)$ indicates significant differences $(\mathrm{p}<0.05)$ between treatments connected by solid lines. Data are expressed as mean \pm 1 standard error $(n=4-6)$.

after $48 \mathrm{~h}$ of arsenic exposure (Ventura-Lima et al., 2009a, 2009b) and also in mammalian cells that concomitantly enhanced GCL activity, the key enzyme involved in GSH synthesis (Schuliga et al., 2002). These results suggest that increased GSH levels could be an early response to As exposure, likely offering protection against As toxicity.

Some studies have shown that treatment with antioxidants can improve the growth ratio, immune responses and resistance of shrimp against pathogens (Chang et al., 2012), but a limited knowledge is available on potential effects in terms of protection against chemical pollutants. Similar information would be of particular value for farmed shrimp that are susceptible to such environmental stressors, potentially leading to oxidative stress diseases. In addition, the use of antioxidants through the feed might also improve the antioxidant capacity of shrimp and increase the quality of the product.

Among such compounds, lipoic acid is known as a powerful antioxidant due to its ability of being a ROS scavenger, regenerate other endogenous antioxidants, metal chelating activity and expression of key antioxidant enzymes (Gorąca et al., 2011). The treatment with LA has been shown to enhance the antioxidant responses in rat liver after Cd exposure (Sumathi et al., 1996), but similar effects remain unexplored for aquatic organisms.

In this study, pre-treatment with LA caused a significant decrease of ROS concentration in hepatopancreas of control organisms (+ LA) and in those exposed concomitantly to Cd and As (Fig. 1b). The antioxidant competence against peroxyl radicals was increased in the same groups (Fig. 4a), suggesting that LA can act as a scavenger of these specific ROS; interestingly, these effects were not observed in the groups exposed separately to $\mathrm{Cd}$ or As, confirming that chemical mixtures can provoke oxidative effects different from those expected by individual
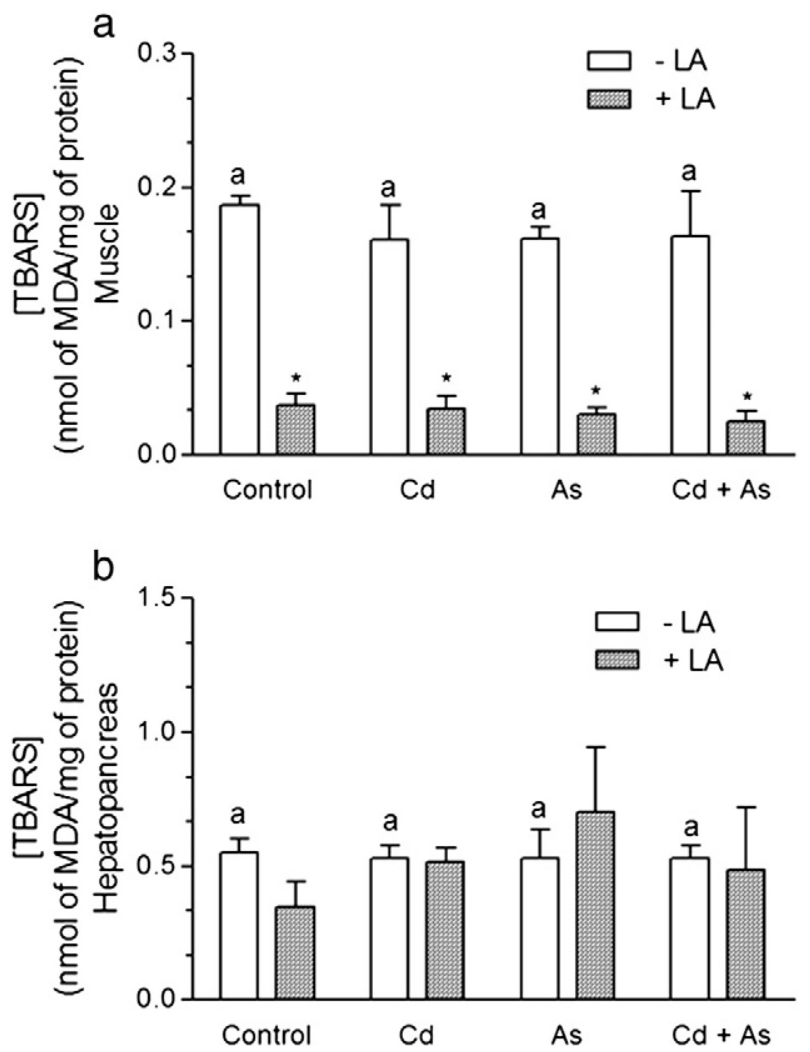

Fig. 5. Thiobarbituric acid reactive substance (TBARS) content (expressed as nmol of $\mathrm{MDA} / \mathrm{mg}$ of protein). (a) Muscle; (b) hepatopancreas. Different letters indicate significant differences $(\mathrm{p}<0.05)$ compared to control group $(-\mathrm{LA})$. Asterisks $\left({ }^{*}\right)$ indicate significant difference $(\mathrm{p}<0.05)$ between group pre-treated with LA $(+\mathrm{LA})$ when compared with same treatment without LA $(-\mathrm{LA})$. Data are expressed as mean \pm 1 standard error $(n=4-6)$.

chemicals (Regoli et al., 2005; Benedetti et al., 2007, 2009). A decrease of ROS concentration was previously reported in brain of $C$. paleatus after four weeks treatment with LA through feed (Monserrat et al., 2008), suggesting that the same properties that make of LA a power antioxidant in mammals system can also be applied to aquatic organism as scavenger of ROS.

Pre-treatment with LA improved the antioxidant capacity of shrimp at least partly by increasing the GSH levels in hepatopancreas (Fig. 3b); the same effect, caused by exposure to As alone, was reversed by pre-treatment with LA. Arsenic is known to promote the nuclear migration of transcriptional Nrf2 factor, promoting the expression of a gene battery for antioxidant and detoxification enzymes including GCL, responsible for GSH synthesis (Wang et al., 2007; Jiang et al., 2009). Arsenic exposure enhanced GSH levels in mammalian cells trough Nrf2 expression (Pi et al., 2008) and by acting as an As-chelator, LA would prevent the Nrf2-mediated modulation of GSH metabolism.

In muscle GSH levels were lowered after $\mathrm{Cd}$ and $\mathrm{Cd}+$ As exposures (Fig. 3a), consistent with metal binding to thiolic groups. Our results showed that pre-treatment with LA can revert this effect maintaining basal levels of GSH, and confirming the metal-chelating ability of this antioxidant which prevents the interaction of Cd with GSH. Similar to our findings, Sumathi et al. (1996) observed decreased GSH content in liver and kidney of rats exposed to Cd, and restored levels after treatment with LA.

The GSTs are involved in oxidative protection and metabolism of xenobiotics through GSH conjugation. In our study, LA enhanced these enzymatic activities in muscle and hepatopancreas of shrimp (Fig. 2a and $b$, respectively), supporting the utility of LA to improve the detoxification capacity and resistance against pollutant toxicity in different organs of aquatic organisms. Previous results indicated that pre-treatment 

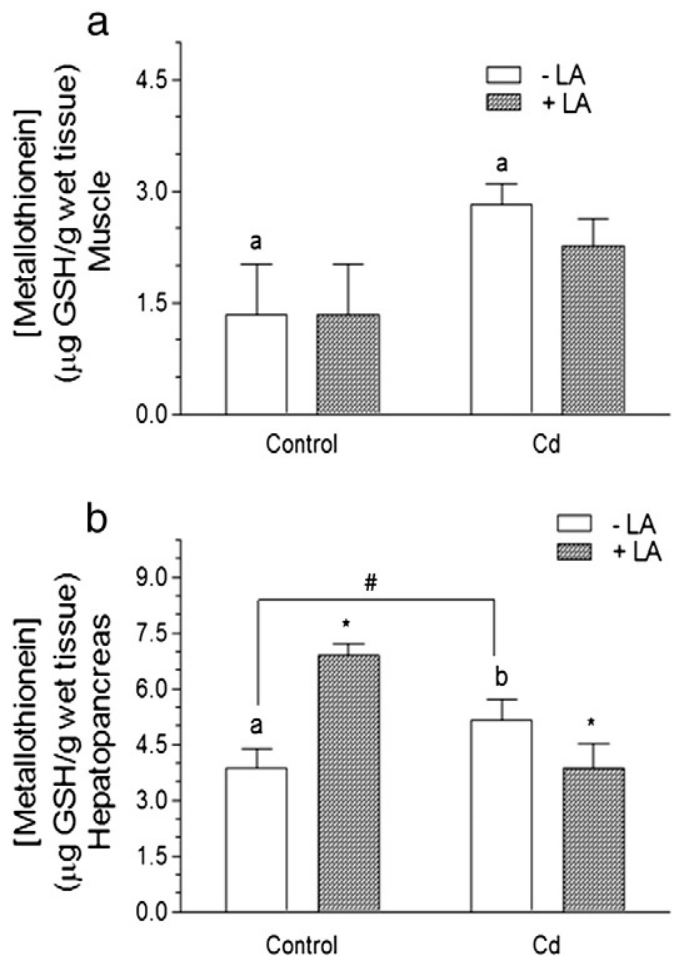

Fig. 6. Metallothionein-like content (expressed as $\mu \mathrm{g} \mathrm{GSH} / \mathrm{mg}$ of wet tissue). (a) Muscle; (b) hepatopancreas. Different letters indicate significant differences $(\mathrm{p}<0.05)$ compared to control group $(-\mathrm{LA})$. Asterisks $\left(^{*}\right)$ indicate significant difference $(\mathrm{p}<0.05)$ between group pre-treated with LA ( + LA) when compared with same treatment without LA $(-\mathrm{LA})$. Hash $(\#)$ indicates significant differences $(\mathrm{p}<0.05)$ between treatments connected by solid lines. Data are expressed as mean \pm 1 standard error $(n=4-6)$.

of fishes with LA caused a stimulation of GST activity in brain and liver of C. carpio exposed to hepatotoxin microcystin (Amado et al., 2011) and in brain of $C$. paleatus (Monserrat et al., 2008). This study revealed that LA enhanced also the levels of MT-L in control organisms, further increasing the antioxidant and detoxification capacity of hepatopancreas (Fig. 6b). Although gene expression was not measured in shrimp, the increase of both GST activity and MT-like levels could be dependent on modulation of Nrf2 by LA. Some antioxidants have the potential to activate Nrf2 and expression of genes containing antioxidant-responsive elements (ARE). In hepatocyte cell lines the pre-treatment with quercetin increased MT levels through this pathway and a similar result was observed in HepG2 cells treated with LA (Weng et al., 2011). On the other hand, the hepatopancreas of shrimp pre-treated with LA and then exposed to Cd exhibited a decrease in MT-like levels when compared to the group exposed only to Cd (Fig. 6a). This result could be caused by the interaction between LA and $\mathrm{Cd}$, the first becoming less available to induce Nrf2 expression; however, more studies are necessary to confirm this hypothesis.

No oxidative damage was highlighted in this study in terms of lipid peroxidation, and the pre-treatment with LA caused a marked decrease of TBARS in the muscle of either control and exposed organisms (Fig. 5a). Treatment with LA was previously shown to reduce the oxidized protein levels in the muscle of fish $C$. paleatus, compared to control group that did not receive LA (Monserrat et al., 2008), indicating the effectiveness of this antioxidant in reducing oxidative stress parameters, this peculiarity is important for an organ like muscle, which is the edible portion of L. vannamei, a broadly framed species in aquaculture.

Although the limited knowledge of LA effects on shrimp species such as L. vannamei, the results from this study suggest various antioxidant properties of this compound: its supplementation through diet appeared to have chelating metal properties lowering bioavailabity of Cd and As, ROS-scavenging efficiency, and the capability to improve antioxidant and detoxification capacities. These data suggest that diets rich in lipoic acid are beneficial for antioxidant protection and could be used as a chemoprevention strategy against oxidative insults in farmed shrimp.

\section{Grants, sponsors and funding sources}

The authors wish to thank Fundação de Amparo à Pesquisa do Estado do Rio Grande do Sul (FAPERGS) for the financial support (Programa ARD/2010). Roberta de Oliveira Lobato is a graduate fellow from the Brazilian Agency CAPES. Silvana Manske is undergraduate fellow from CNPq. Juliane Ventura-Lima received a post-doctoral fellow from Coordenação de aperfeiçoamento de pessoal de nível superior (CAPES/Programa Ciências do Mar/2009). José Monserrat and Wilson Wasielesky are research fellows from CNPq.

\section{References}

Amado, L.L., Garcia, M.L., Ramos, P.B., Freitas, R.F., Zafalon, B., Ferreira, J.L.R., Yunes, J.S Monserrat, J.M., 2009. A method to measure total antioxidant capacity against peroxyl radicals in aquatic organisms: application to evaluate microcystins toxicity. Sci. Total. Environ. 407, 2123-2215.

Amado, L.L., Garcia, M.L., Pereira, T.C.B., Yunes, J.S., Bogo, M.R., Monserrat, J.M., 2011 Chemoprotection of lipoic acid against microcystin-induced toxicosis in common carp (Cyprinus carpio, Cyprinidae). Comp. Biochem. Physiol. C 154, 146-153.

Anderson, R.S., Patel, K.M., Roesijadi, G., 1999. Oyster metallothionein as an oxyradical scavenger: implications for hemocyte defense responses. Dev. Comp. Immunol. 23 443-449.

Bagyuokova, T.V., Luzhna, L.L., Pogribny, I.P., Lushchak, V.L., 2007. Oxidative stress and antioxidant defenses in goldfish liver in response to short-term exposure to arsenite. Environ. Mol. Mutagen. 48, 658-665.

Benedetti, M., Martuccio, G., Fattorini, D., Canapa, A., Barucca, M., Nigro, M., Regoli, F., 2007. Oxidative and modulatory effects of trace metals on metabolism of polycyclic aromatic hydrocarbons in the Antarctic fish Trematomus bernacchii. Aquat. Toxicol. 85, 167-175.

Benedetti, M., Fattorini, D., Martuccio, G., Nigro, M., Regoli, F., 2009. Interactions between trace metals $(\mathrm{Cu}, \mathrm{Hg}, \mathrm{Ni}, \mathrm{Pb})$ and 2,3,7,8-tetrachlorodibenzo-p-dioxin in the Antarctic fish Trematomus bernacchii: oxidative effects on biotransformation pathway. Environ. Toxicol. Chem. 28, 818-825.

Chang, M., Wang, W.-N., Wang, A.-L., Tian, T.-T., Wang, P., Zheng, Y., Liu, Y., 2009 Effects of cadmium on respiratory burst, intracellular $\mathrm{Ca}^{2+}$ and DNA damage in the white shrimp Litopenaeus vannamei. Comp. Biochem. Physiol. C 149, 581-586.

Chang, Y.-P., Liu, C.-H., Wu, C.-C., Chiang, C.-M., Lian, J.-L., Hsieh, S.-L., 2012. Dietary administration of zingerone to enhance growth, non-specific immune response and resistance to Vibrio alginolyticus in Pacific white shrimp (Litopenaeus vannamei) juveniles. Fish Shellfish Immunol. 32, 284-290.

Chelonin, V.P., Zakharstsev, M.V., Kurilenko, A.V., Belcheva, N.N., 2005. An in vitro study of the effect of reactive oxygen species on subcellular distribution of deposited cadmium in digestive gland of mussel Crenomytilus grayanus. Aquat. Toxicol. 73 , $181-189$.

Dabas, A., Nagpure, N.S., Kumar, R., Kushawara, B., Kumar, P., Lakra, W.S., 2012. Assessment of tissue-specific effect of cadmium on antioxidant defense system and lipid peroxidation in freshwater murrel, Channa punctatus. Fish Physiol. Biochem. 38, 469-482.

Espinoza, H.M., Williams, C.R., Gallagher, E.P., 2012. Effect of cadmium on glutathioneS-transferase and metallothioneins gene expression on coho salmon liver, gills and olfactory tissues. Aquat. Toxicol. 110-111, 37-44.

Fattorini, D., Notti, A., Di Mento, R., Cicero, A.M., Gabellini, M., Russo, A., Regoli, F., 2008 Seasonal and inter-annual variations of trace metals in mussels from the Adriatic Sea: a regional gradient for arsenic and implications for monitoring the impact of off-shore activities. Chemosphere 72, 1524-1533.

Ferreira-Cravo, M., Reinhardt Piedras, F., Moraes, T.B., Ferreira, J.L.R., Salomão, D.P.F., Dornelles Machado, M., Geracitano, L.A., Monserrat, J.M., 2007. Antioxidant responses and reactive oxygen species generation in different body regions of the estuarine polychaeta Laeonereis acuta (Nereididae). Chemosphere 66, 1367-1374.

Frías-Espericueta, M.G., Voltolina, D., Osuna-López, I., Izaguirre-Fierro, G., 2009. Toxicity of metal mixture to the Pacific white shrimp Litopenaeus vannamei post-larvae. Mar. Environ. Res. 68, 223-226.

Gorąca, A., Huk-Kolega, H., Piechota, A., Kleniewska, P., Ciejka, E., Skibska, B., 2011. Lipoic acid-biological activity and therapeutic potential. Pharmacol. Rep. 63, 849-858.

Habig, N.H., Jakoby, W.B., 1981. Assays for differentiation of glutathione-S-transferase Methods Enzymol. 77, 398-405.

Halliwell, B., Gutteridge, J.M.C., 2007. Free Radicals in Biology and Medicine. Oxford University Press Inc. New York (851 pp.).

Hossain, M.F., 2006. Arsenic contamination in Bangladesh-an overview. Agric. Ecosyst. Environ. 113, 1-16.

Hsieh, T.-J., Wang, J.-C., Hu, C.-H., Li, C.-T., Kuo, C.-M., 2008. Effects of Rutin from Toona sinensis on the immune and physiological responses of white shrimp (Litopenaeus vannamei) under Vibrio alginolyticus challenge. Fish Shellfish Immunol. 25, 581-588.

Jiang, T., Huang, Z., Chan, J.Y., Zhang, D.D., 2009. Nrf2 protects against As(III)-induced damage in mouse liver and bladder. Toxicol. Appl. Pharmacol. 240, 8-14. 
Latire, T., Le Pabic, C., Mottin, E., Mottier, A., Costil, K., Koueta, N., Lebel, J.-M., Serpentini, A., 2012. Responses of primary cultured haemocytes from the marine gastropod Haliotis tuberculata under 10-day exposure to cadmium chloride. Aquat. Toxicol. 109, 213-221.

Mirlean, N., Roisemberg, A., 2006. The effect of emissions of fertilizer production on the environment contamination by cadmium and arsenic in southern Brazil. Environ. Pollut. 143, 335-340.

Monserrat, J.M., Ventura-Lima, J, Ribas-Ferreira, J.L. Acosta, D. Garcia, M.L., Ramos, P.B., Moraes, T.B., Santos, L.C., Amado, L.L., 2008. Modulation of antioxidant and detoxification response mediated by lipoic acid in the fish Corydoras paleatus (Callychthyidae). Comp. Biochem. Physiol. C 148, 287-296.

Oakes, K.D., Van Der Kraak, G.J., 2003. Utility of the TBARS assay in detecting oxidative stress in white sucker (Catostomus commersoni) populations exposed to pulp mill effluent. Aquat. Toxicol. 63, 447-460.

Packer, L., Witt, E.H., Tritschler, H.J., 1995. Alpha-lipoic acid as biological antioxidant Free Radic. Biol. Med. 19 (227), 250.

Pi, J., Diwan, B.A., Sun, Y., Liu, J., Qu, W., He, Y., Styblo, M., Waalkes, M.P., 2008. Arsenicinduced malignant transformation of human keratinocytes: involvement of Nrf2. Free Radic. Biol. Med. 45, 651-658.

Regoli, F., Nigro, M., Benedetti, M., Gorbi, S., Pretti, C., Gervasi, P.G., Fattorini, D., 2005. Interactions between metabolism of trace metals and xenobiotic agonists of the Ah receptor in the Antarctic fish Trematomus bernacchii: environmental perspectives. Environ. Toxicol. Chem. 24 (6), 1475-1482.

Roesijadi, G., Brubacher, L.L., Unger, M.E., Anderson, R.S., 1997. Metallothionein mRNA induction and generation of reactive oxygen species in molluscan hemocytes exposed to cadmium in vitro. Comp. Biochem. Physiol. C 118, 171-176.

Samuel, S., Kathirvel, R., Jayavelu, T., Chinnakkannu, P., 2004. Protein oxidative damage in arsenic induced rat brain: influence of DL- $\alpha$-lipoic acid. Toxicol. Lett. 155, 27-34.

Sant'Ana, L.S., Mancini-Filho, J., 2000. Influence of addition of antioxidants in vivo on the fatty acid composition of fish fillet. Food Chem. 68, 175-178.

Schuliga, M., Chouchane, S., Snow, E.T., 2002. Up-regulation of glutathione-related genes and enzyme activities in cultured human cells by sub-lethal concentration of inorganic arsenic. Toxicol. Sci. 70, 183-192.
Soares, S.S., Martins, H., Gutierrez-Merino, C., Aureliano, M., 2008. Vanadium and cadmium in vivo effects in teleost cardiac muscle: metal accumulation and oxidative stress markers. Comp. Biochem. Physiol. C 147, 168-178.

Sumathi, R., Govindarajan, B., Varalakshmi, P., 1996. Effect of DL $\alpha$-lipoic acid on tissue redox state in acute cadmium-challenged tissue. J. Nutr. Biochem. 7, 85-92.

Ventura-Lima, J., Castro, M.R., Acosta, D., Fattorini, D., Regoli, F., Carvalho, L.M., Bohrer, D., Geracitano, L.A., Barros, D.M., Silva, R.S., Bonan, C.D., Bogo, M.R., Monserrat, J.M., 2009a. Effects of arsenic (As) exposure on the antioxidant status of gills of the zebrafish Danio rerio (Cypridinae). Comp. Biochem. Physiol. C 149, 538-543.

Ventura-Lima, J., Fattorini, D., Regoli, F., Monserrat, J.M., 2009b. Effects of different inorganic arsenic species in Cyprinus carpio (Cyprinidae) tissues after short-time exposure: bioaccumulation, biotransformation and biological responses. Environ. Pollut. 157, 3479-3484

Viarengo, A., Ponzano, E., Dondero, F., Fabbri, R., 1997. A simple spectrophotometric method for metallothionein evaluation in marine organisms: an application to Mediterranean and Antarctic molluscs. Mar. Environ. Res. 44, 69-84.

Wang, X.-J., Sun, Z., Chen, W., Eblin, K.E., Gandolfi, J.A., Zhang, D.D., 2007. Nrf2 protects human bladder urothelial cells from arsenite and monomethylarsonous acid toxicity. Toxicol. Appl. Pharmacol. 225, 206-213.

Weng, C.-J., Chen, M.-J., Yeh, C.-T., Yen, G.-C., 2011. Hepatoprotection of quercetin against oxidative stress by induction of metallothionein expression through activating MAPK and PI3K pathways and enhancing Nrf2 DNA-binding activity. New Biotechnol. 28, 766-777.

White, C.C., Viernes, H., Krejsa, C.M., Botta, D., Kavanagh, T.J., 2003. Fluorescence-based microtiter plate assay for glutamate-cysteine ligase activity. Anal. Biochem. 318, 175-180.

Winston, G.N., Regoli, F., Dugas Jr., A.J., Fong, J.H., Blanchard, K.A., 1998. A rapid gas chromatographic assay for determining oxyradical scavenging capacity of antioxidant and biological fluids. Free Radic. Biol. Med. 24, 480-493.

Zar, J.H., 1984. Biostatistical Analysis. Prentice Hall, New Jersey. 